\title{
ПРИНЦИП ПРОПОРЦИОНАЛЬНОСТИ В СУДЕБНЫХ РЕШЕНИЯХ ПО ИЗБИРАТЕЛЬНЫМ СПОРАМ КАК АДЕКВАТНАЯ ФОРМА ЗАЩИТЫ АКТИВНОГО И ПАССИВНОГО ИЗБИРАТЕЛЬНОГО ПРАВА
}

Аннотация: В статье на основе анализа решений Европейского суда по правам человека и российских судебных органов рассматривается процесс применения при разрешении избирательных споров принципа пропорциональности, который можно рассматривать в качестве одного из правовых средств, позволяющих гарантировать реализацию публичного интереса в условиях демократического государства, отразить в процессе правоприменения баланс интересов различных его участников. Использование принципа пропорциональности позволяет понять логику правоприменителя, которая находит отражение в принятом им решении. В ходе исследования соотносятся позиции Европейского суда по правам человека с решениями Конституционного Суда Российской Федерации, проводится анализ решений иных судебных органов Российской Федерации, при принятии которых, по мнению автора, нашел реализацию принцип пропорциональности. Автором предлагается закрепить в нормативных правовых актах, регулирующих избирательные правоотношения, цели их принятия. Это предоставит правоприменителю возможность правильно определить для себя цель правового регулирования, на основе которой будет осуществляться толкование нормативных положений. Данное требование должно найти отражение в актах, определяющих порядок принятия и содержания нормативных правовых актов как федеральных, так и региональных и местных уровней.

Ключевые слова: выборы, Конституционный Суд РФ, пропорциональность, избирательное право, избирательная кампания, кандидат, подкуп избирателей, закон, подписной лист, депутат.

DOI: 10.7256/1994-1471.2014.6.10755

$\mathrm{B}$ избирательном процессе, как и в любой другой деятельности, возникают ситуации, когда цель, заложенная в нормативном акте при его принятии, и цель, реализуемая отдельным участником избирательной кампании, могут противоречить друг другу. В этом случае правоприменителю следует выбрать наиболее значимую из них в конкретных правоотношениях. Это может быть достигнуто посредством использования принципа пропорциональности, применение которого характерно для правовых систем европейских государств. В правовой литературе его возникновение часто связывается с традициями германского конституционализма, а его истоки усматриваются в доктрине прусского адми- нистративного права ${ }^{1}$. Этот принцип, включающий в себя три элемента - адекватность, необходимость, соразмерность, иногда понимаемых как степени контроля, выводится судебной практикой из положений конституции и применяется главным образом в сфере защиты прав человека.

Современное содержание принципа пропорциональности во многом сформировалось под влиянием практики Европейского суда по правам человека, решения которого обя-

\footnotetext{
Шерстобоев О.Н. Принцип пропорциональности как необходимое условие высылки иностранных граждан за пределы государства их пребывания: пределы правоограничения // Российский юридический журнал. 2011. № 6 (81). С. 52.
}

(C) Макарцев Андрей Алексеевич

Кандидат юридических наук, доцент кафедры конституционного и международного права, Сибирский университет потребительской кооперации

[Makarzew@mail.ru]

630087, Россия, г. Новосибирск, пр. К.Маркса, д. 26. 
зательны как для стран континентальной правовой семьи, так и для Великобритании. В литературе отмечается, что в США рассматриваемый принцип в европейском смысле не используется, но американские суды исследуют баланс цели правового регулирования и средства её достижения, в том числе и в сфере избирательных отношений, а ученые посредством его применения определяют направления дальнейшего развития законодательства $^{2}$. Так, по мнению американских правоведов, проблема определения равновесия в финансировании избирательных кампаний между партиями и кандидатами, с одной стороны, и частными корпорациями - с другой, является актуальной в современной американской политической и правовой практике. Согласно их предположению, государство должно выбрать своей приоритетной целью финансирование избирательных кампаний за счет финансовых средств политических партий и кандидатов. В случае участия в финансировании избирательных кампаний крупных негосударственных корпораций выборы теряют свою сущность, и превращаются в борьбу «денежных мешков»³.

Применению принципа пропорциональности судебными органами Российской Федерации способствовало признание Российской Федерацией решений Европейского суда по правам человека, в которых он получил наибольшее развитие в качестве средства обоснования решения, в том числе и по делам, связанным с защитой избирательных прав. Европейский суд по правам человека не только разрешает дело, но и предпринимает попытки определить цели, преследуемые правоприменителем при разрешении конкретного дела, выявить его мотивы. Так, им было удовлетворено заявление Ю. И. Скуратова, которому было отказано в регистрации в качестве кандидата в депутаты Государственной Думы Федерального Собрания Российской Федерации четвертого созыва на основании того, что в качестве места работы, должности им была указана «должность исполняющего обязанности заведующего кафедрой конституционного, административного и международного права» одного из московских вузов, но при этом не был указан статус профессора кафедры. В действующем на тот момент избирательном

Cohen-Eliya M., Stopler G. Probability Thresholds as Deontological in Global Constitutionalism // Columbia Journal of Transnational Law. 2011. Vol. 24. № 1. - P. 77.

Restoring electoral equilibrium in the wake of constituonalized campaign finance // Harvard Law Review. 2011. Vol. 124. № 6. // http://www.harvardlawreview.org/ media/pdf /vol124_restoring_electoral_equilibrium.pdf (последнее посещение 25 декабря 2013 г.). законодательстве было закреплено положение, согласно которому основанием для отказа в регистрации могла быть недостоверность сведений, представляемых кандидатом для регистрации, и отсутствие необходимых документов. По мнению Европейского суда по правам человека, выводы правоприменительных органов Российской Федерации не были основаны на нормах Закона или практике его толкования: «Нельзя серьезно утверждать, что различие между должностью профессора кафедры и исполняющего обязанности заведующего этой же кафедрой могло бы ввести избирателей в заблуждение» ${ }^{4}$.

Европейский суд по правам человека, мотивировав свою правовую позицию положением ст. 3 Протокола № 1 Конвенции о защите прав человека и основных свобод (Рим, 4 ноября 1950 г. $)^{5}$, попытался определить «законность цели», к которой стремились российские власти при принятии решения об отстранении Ю. И. Скуратова от участия в выборах. Как отмечается в литературе, фактически при рассмотрении этого дела Европейский суд по правам человека определял не соответствие принятого решения нормам материального Закона, применяемого к данным правоотношениям, а попытался определить и дать оценку мотивам и умыслу принятого решения ${ }^{6}$.

Принцип пропорциональности использовался Европейским судом по правам человека и при рассмотрении жалобы, которая касалась запрета на участие в выборах лиц, содержащихся в местах лишения свободы по приговору суда, закрепленного ч. 3 ст. 32 Конституции Российской Федерации. Заявители по делу, российские граждане Сергей Анчугов и Владимир Гладков, в силу этого запрета не смогли принять участие в парламентских и президентских выборах. Предпринималась попытка оспорить этот запрет в Конституционном Суде Российской Федерации. Однако в рассмотрении жалобы отказывалось, поскольку разрешение поставленного в ней вопроса Конституционному Суду Российской Федерации было

\footnotetext{
4 Постановление ЕСПЧ от 19 июля 2007 г. Дело «Краснов и Скуратов (Krasnov and Skuratov) против Российской Федерации» (жалоба № 17864/04 и 21396/04) // Бюллетень Европейского суда по правам человека.
} 2008. № 4 .

Международные избирательные стандарты. Сборник документов / отв. ред. А.А. Вешняков. М.: Издательство ВЕСЬ МИР, 2004. С. 536.

Борисов И.Б., Ивайловский Д.А. Соотношение отдельных позиций Европейского суда по правам человека с национальным избирательным законодательством // Конституционное и муниципальное право. 2009. № 3. C. 27. 
неподведомственно ${ }^{7}$. Поданные С. Анчуговым и В. Гладковым в суды общей юрисдикции жалобы на действия (бездействия) избирательных комиссий, как отмечается в решении Европейского суда по правам человека, либо возвращались по формальным причинам, либо не удовлетворялись.

Европейский суд по правам человека согласился, что государство имеет широкое усмотрение в ограничении избирательного права, однако оно должно быть соразмерным. Лишение права на голосование при заключении на любой срок таковым не является. В своем решении по делу № № 11157/04 и 15162/05 «Анчугов и Гладков против России» (Anchugov and Gladkov v. Russi) Суд отметил, что участие в выборах в современном обществе является не привилегией, а презюмируемым правом. ЕСПЧ посчитал, что запрет, предусмотренный ст. 32 Конституции Российской Федерации, нарушает ст. 3 Протокола № 1 Конвенции о защите прав человека и основных свобод. Решение о лишении избирательных прав должно приниматься судьей, с учетом всех конкретных обстоятельств ${ }^{8}$.

С одной стороны, можно согласиться с положениями, обосновывающими решение Европейского суда по правам человека: фактически лишение избирательных прав лиц, находящихся в местах лишения свободы по приговору суда за совершение преступлений любой тяжести, является не предусмотренной Уголовным кодексом Российской Федерации санкцией. Подход, связывающий возможность ограничения избирательных прав со сроками судимостей, нашел отражение в Постановлении Конституционного Суда Российской Федерации от 10 октября 2013 г. № 20-П «По делу о проверке конституционности подпункта "а" пункта 3.2 статьи 4 Федерального закона “Об основных гарантиях избирательных прав и права на участие в референдуме граждан Российской Федерации", части первой статьи 10 и части шестой статьи 86 Уголовного кодекса Российской Федерации в связи с жалобами граждан Г. Б. Егорова, А. Л. Казакова, И. Ю. Кравцова, А. В. Куприянова, А. С. Латыпова и В. Ю. Синькова». Конституционный Суд Российской Федерации отметил, что сроки вводимых федеральным законом ограничений пассивного избирательного права,

Определение Конституционного Суда Российской Федерации от 27.05.2004 № 177-О «Об отказе в принятии к рассмотрению жалобы гражданина Гладкова Владимира Михайловича на нарушение его конституционных прав статьей 32 (часть 3) Конституции Российской Федерации» // СПС КонсультантПлюс.

Anchugov and Gladkov v. Russi (№ № 11157/04 и 15162/05) // Бюллетень Европейского Суда по правам человека. 2013. № 8 . по общему правилу, должны устанавливаться соответственно дифференциации сроков судимости, предусмотренных Уголовным кодексом Российской Федерации ${ }^{9}$. Необходимо отметить, что упомянутое Постановление Конституционного Суда Российской Федерации принято в рамках другого решения Европейского суда по правам человека от 8 апреля 2010 г. «Фродль против Австрии» ${ }^{10}$, в соответствии с которым обстоятельства, при которых возможно лишение права на участие в голосовании, должны быть подробно изложены в законе, который должен регламентировать их применение в зависимости от такого фактора, как тяжесть совершенного преступления. Государства могли бы относить пропорциональность меры ограничения избирательных прав заключенных на усмотрение судов или включать в законодательство положения, определяющие обстоятельства, при которых применяется такая мера. В последнем случае сам законодатель должен сопоставить конкурирующие интересы в целях избежать любого общего, автоматического и неизбирательного ограничения.

С другой стороны, при рассмотрении дела «Анчугов и Гладков против России» необходимо было принимать во внимание, что подход, связанный с ограничением избирательных прав лиц, находящихся в местах лишения свободы по решению суда, является традиционным не только для российского законодательства, но и для российской правовой науки. Еще в начале XX в. В.М. Гессен писал о необходимости ограничения избирательных прав лиц, которые «осуждены по суду за позорящие преступления» ${ }^{11}$. Также можно согласится с В. Д. Зорькиным, который отмечает, что «Конституция Российской Федерации в ст. 15 устанавливает приоритет международного договора над положением закона, но не над положениями Конституции. Монополия на истолкование Конституции и выявление конституционного смысла закона принадлежит Конституционному Суду. И поэтому истолкование Конституции, данное высшим судебным органом государства, не может быть преодолено путем истолкования Конвенции, поскольку ее юридическая сила все-таки юридическую силу Конституции не превосходит» ${ }^{12}$.

\section{Рос. газ. 2013. № 238.}

10 Постановление ЕСПЧ от 8 апреля от 8 апреля 2010 г. «Фродль против Австрии» (Frodi v. Austria), жалоба № 20201/04 // СПС КонсультантПлюс.

11 Гессен В.М. Русское Учредительное собрание и выборы в него // Политические институты, избирательное право и процесс в трудах российских мыслителей XIX-XX вв. Хрестоматия. М.: «Весь Мир», 2003. С. 610.

12 Зорькин В.Д. Предел уступчивости // Российская газета. 2010. № 5325 (246). 
Несмотря на это, в своем решении Европейский суд по правам человека отметил, что государство несет ответственность по ст. 1 Конвенции о защите прав человека и основных свобод независимо от вида акта, нарушающего права, предусмотренные Конвенцией и Протоколами к ней. Суд не принял во внимание аргумент Российской Федерации о сложности процедуры изменения второй главы Конституции Российской Федерации, обосновав это тем, что его роль заключается в оценке соответствия запрета требованиям Конвенции. По мнению Суда, российские власти могут избрать любой доступный им способ устранить нарушение: например, толкование Конституционным Судом Российской Федерации конституционных положений таким образом, чтобы последние не противоречили Конвенции. Необходимо отметить, что аналогичное решение по вопросу запрета участвовать в выборах лицам, находящимся в местах лишения свободы по приговору суда, было принято Комитетом по правам человека ООН по делу «Денис Евдокимов и Артем Резанов против Российской Федерации». Комитет признал этот запрет не соответствующим требованиям Международного пакта о гражданских и политических правах. По его мнению, если основанием для временного лишения права голоса является осуждение в связи с совершенным преступлением, то срок, на который действие этого права приостановлено, должен быть соразмерным тяжести преступления и вынесенному приговору ${ }^{13}$.

Проводя анализ решения Европейского суда по правам человека по делу «Анчугов и Гладков против России», следует отметить, что позиция, которая в нем выражена, не является исключительным подходом Суда в определении рамок реализации субъективного избирательного права только в отношении правового регулирования в Российской Федерации. Аналогичный подход нашел отражение в решении Европейского суда по правам человека по делу «Хёрст (Hirst) против Соединенного Королевства)», в котором обращалось внимание на «отсутствие рационального объяснения существования нормы закона, направленной на лишение лиц избирательных прав, осужденных за совершение преступления» ${ }^{14}$.

13 Решение Комитета ООН по правам человека № 1410/2005 по заявлению Дениса Евдокимова и Артема Резанова против Российской Федерации // http://www1.umn.edu/humanrts/russian/hrcommittee/ Rview1410sess101.html (дата доступа 25 декабря 2013 г.).

14 Постановление ЕСПЧ от 6 октября 2005 г. «Дело «Херст (Hirst) против Соединенного Королевства (№ 2)» // Бюллетень Европейского суда по правам человека. 2006. № 4.
Принцип пропорциональности подразумевает необходимость тщательного анализа правоприменителями всех обстоятельств избирательного спора. Проблема осложняется тем, что им часто приходится полагаться на собственное усмотрение. Отсутствие в нормативном правовом акте четко закрепленных целей его реализации проводит к тому, что недостаточно компетентный правоприменитель неправильно его понимает. Довольно ярко, по нашему мнению, это проявилось в решении Молчановского районного суда Томской области от 19 февраля 2008 г. № 33-576/08 о признании результатов выборов главы Молчановского района, проведенных 2 декабря 2007 г., недействительными. Судом при рассмотрении дела было установлено, что в ходе проведения оспариваемых выборов имели место нарушения законодательства: за избирателей голосовали другие лица, не соблюдались правила голосования вне помещения для голосования, осуществлялся подкуп избирателей. В судебном решении обращалось внимание на то, что установить действительную волю четырнадцати избирателей не представляется возможным, а воля одного избирателя была учтена избирательной комиссией незаконно, так как он не обладал активным избирательным правом (в судебном решении не нашло отражение, за кого он голосовал). Голоса избирателей, содержание волеизъявления которых установить было невозможно, суд отнял от общего количества голосов, полученных победителем - кандидатом С. В итоге С. получил менее пятидесяти процентов голосов избирателей, что привело к признанию судом результатов выборов недействительными. Это решение нашло подтверждение в Судебной коллегии по гражданским делам Томского областного суда ${ }^{15}$. По нашему мнению, у суда была возможность, разделив недействительные голоса между всеми кандидатами, признать выборы состоявшимися. Но поставленная судом цель установления действительной воли избирателей отодвинула на второй план необходимость установления итогов голосования.

Применение пропорциональности чаще всего характерно для избирательных споров, связанных с отменой регистрации кандидата, когда судья оценивает правонарушение, совершенное кандидатом (избирательным объединением) и его возможное влияние на результаты голосования. В этом отношении интересно дело, связанное с выборами главы Каргатского района Новосибирской области. Муниципаль-

Кассационное определение от 9 апреля 2008 г. Судебной коллегии по гражданским делам Томского областного суда. С. 9. 
ная избирательная комиссия Каргатского района Новосибирской области обратилась в суд с заявлением об отмене регистрации кандидата на должность главы Каргатского района Новосибирской области П., ссылаясь на то, что последний в ходе избирательной кампании осуществлял подкуп избирателей: 29 ноября 2008 г. во время проведения публичного предвыборного мероприятия в селе Маршанское в сельском доме культуры П. лично бесплатно раздавал цветы и конфеты, сопровождая эти действия призывами прийти на выборы и голосовать за него. Суд Каргатского района удовлетворил требование муниципальной избирательной комиссии.

Новосибирский областной суд с выводами суда первой инстанции не согласился. В кассационном решении отмечалось, что в судебном заседании не был установлен факт именно подкупа избирателей. Допрошенные судом свидетели показали, что П. дарил цветы и конфеты не всем избирателям, а только некоторым многодетным матерям, поздравляя их с Днем матери ${ }^{16}$. Решение кассационной инстанции фактически расширило содержание п. 2 ст. ст. 58 Федерального закона «Об основных гарантиях избирательных прав и права на участие в референдуме граждан Российской Федерации». В соответствии с ним кандидатам, избирательным объединениям, их доверенным лицам и уполномоченным представителям, а также иным лицам и организациям при проведении предвыборной агитации запрещается осуществлять подкуп избирателей, в том числе и вручать им денежные средства, подарки и иные материальные ценности. По мнению суда, по общему правилу кандидат не обладает правом вручать подарки, но исключение составляют праздники, на которых кандидаты могут в качестве поздравления вручать подарки и иные материальные ценности. Фактически суд вывел данные отношения за рамки избирательной кампании. Принимая решение об отсутствии в действиях кандидата подкупа, суд фактически признал, что совершенное кандидатом действие не могло существенно повлиять на результаты голосования в конкретной избирательной кампании.

При этом за рамками судебного решения осталась проблема финансирования деятельности, связанной с вручением подарков. В случае если они приобретаются из средств избирательного фонда, то вручение подарков является составной частью избирательной

\footnotetext{
16 Кассационное определение Новосибирского област ного суда от 16 декабря 2008 г.
}

кампании кандидата, так как в соответствии с п. 2 ст. 59 Федерального закона «Об основных гарантиях избирательных прав и права на участие в референдуме граждан Российской Федерации» средства избирательных фондов могут использоваться кандидатами, избирательными объединениями только на покрытие расходов, связанных с проведением своей избирательной кампании. Если подарки приобретались не из средств избирательного фонда, то фактически мы выводим деятельность, связанную с их вручением кандидатом в период избирательной кампании и направленную на формирование позитивного мнения о кандидате, за рамки избирательной кампании.

Российская избирательная практика показывает, что использование принципа пропорциональности позволяет в ходе процесса правоприменения не только выявить основную цель правовой нормы, но и избежать её подмены второстепенной или промежуточной. Так, решением Новосибирского областного суда от 20 ноября 2001 г. от 20 ноября 2001 г. № 1-322001 была удовлетворена жалоба на решение окружной избирательной комиссии по выборам депутатов Новосибирского областного Совета депутатов. Избирательная комиссия отказала в регистрации кандидату на основании того, что была нарушена форма подписного листа, установленная законом. Нарушение заключалось в отсутствии в нем «Примечания», в котором указывается информация о судимости кандидата, наличии у него депутатского мандата. По мнению суда, отсутствие «Примечания» не является основанием отказа в регистрации кандидата. Подобный подход нашел отражение и в решениях вышестоящих инстанций. Так, согласно Определению Судебной коллегии по гражданским делам Верховного Суда России от 26 ноября 2003 г. № 67-Г03-21 об отказе в удовлетворении заявления об отмене регистрации кандидата в депутаты Государственной Думы Федерального Собрания Российской Федерации ${ }^{17}$, отсутствие «Примечания» не является основанием для отказа в регистрации, так как это нельзя рассматривать как нарушение закона. В отличие от остальной части подписного листа, которая должна в обязательном порядке содержать сведения, предусмотренные Федеральным законом «Об основных гарантиях избирательных прав и права на участие в референдуме граждан Российской Федерации», информация, содержащаяся в «Примечании № 1», является дополнительной и вносится в подписной лист только в том случае, если она в действительности имеет место.

17 СПС КонсультантПлюс. 
В первом случае избирательная комиссия приняла решение, исходя из формальных признаков подписного листа: отсутствие необходимых структурных элементов. Но судебные органы в обоих случаях исходили из основной цели подписного листа: отразить волю избирателя по поводу поддержки в выдвижении того или иного кандидата. Необходимость правильного оформления подписного листа, соблюдение его формы, по мнение судебных органов, хотя и является важным средством процесса регистрации, но не замещает цели выражения волеизъявления избирателей о поддержке кандидатов (списков кандидатов).

С нарушением правил оформления подписного листа связано дело, возникшее в ходе избирательной кампании по выборам депутатов Законодательного Собрания Иркутской области. Кандидат по одномандатному округу № 11 К. в заявлении о самовыдвижении, поданным в избирательную комиссию 17 июля 2013 г., указал о принадлежности к одной из политических партий. С 19 июля его членство в политической партии было прекращено. Проводя проверку представленных 24 июля подписных листов, избирательная комиссия установило нарушение, заключающееся в несоответствии сведений в заявлении о согласии баллотироваться и подписными листами: в подписных листах отсутствовало указание на членство в политической партии. Это обстоятельство, наряду с другими, стало основанием для принятия избирательной комиссией решения об отказе в регистрации, которое было обжаловано К. в суд.

Оценивая обстоятельства дела, суд отметил, что сообщение об изменении ранее представленных сведений, которое носит заявительный характер и осуществляется по инициативе кандидата, в установленные законом сроки в избирательную комиссию от К. не поступало. Поскольку заявитель заведомо знал о прекращении своего членства в политической партии, суд находит несостоятельным довод, что сначала кандидат должен был узнать от избирательной комиссии о возникшем несоответствии между заявлением о согласии баллотироваться и подписными листами, а потом сообщить в комиссию о причинах такого несоответствия.

Возникшее в данном случае несоответствие между заявлением о согласии баллотироваться и подписными листами в части указания на партийную принадлежность имеет существенное правовое значение. Уже после поступления в избирательную комиссию заявления кандидата о согласии баллотироваться избирательными комиссиями осуществляется информирование избирателей о выдвинутых кандидатах. Это информирование как обязательный элемент включает сведения о принадлежности кандидата к политической партии. Следовательно, содержание заявления кандидата о согласии баллотироваться, в части принадлежности к политической партии, могло повлиять на волю избирателя при внесении им подписи в подписной лист в поддержку выдвижения кандидата. В связи с этим суд отказал К. в удовлетворении заявления ${ }^{18}$.

Делая выводы, необходимо отметить, что в контексте разрешения избирательных споров принцип пропорциональности можно рассматривать в качестве одного из правовых средств, позволяющих гарантировать реализацию публичного интереса в условиях демократического государства, отразить в процессе правоприменения баланс интересов различных его участников. Применение принципа пропорциональности позволяет понять логику правоприменителя, которая находит отражение в принятом им решении. Взвесив все обстоятельства дела, правоприменитель выбирает основную, социально значимую цель. По нашему мнению, в избирательных отношениях такой целью служит формирование органов публичной власти на основе демократичных, справедливых выборов, позволяющих учесть мнение большинства избирателей, принявших участие в голосовании. При этом интересы отдельных субъектов избирательного права, проявляясь в процессе достижения основной цели, могут не совпадать, а иногда и противоречить ей.

В связи с этим появляется необходимость закрепления в нормативных правовых актах, регулирующих избирательные правоотношения, цели их принятия. Это предоставит правоприменителю возможность правильно определить для себя цель правового регулирования, на основе которой будет осуществляться толкование нормативных положений. Данное требование должно найти отражение в актах, определяющих порядок принятия и содержания нормативных правовых актов как федеральных, так и региональных и местных уровней.

18 Решение Иркутского областного суда от 16 августа 2013 г. 


\section{Библиография:}

1. Безруков А.В., Казанцев А.О. О необходимости создания конституционных (уставных) судов субъектов Российской Федерации и совершенствования их компетенции // Современное право. 2012. № 7. - С. 106-111.

2. Борисов И.Б., Ивайловский Д.А. Соотношение отдельных позиций Европейского суда по правам человека с национальным избирательным законодательством // Конституционное и муниципальное право. 2009. №-3. - С. 25-29.

3. Гессен В.М. Русское Учредительное собрание и выборы в него // Политические институты, избирательное право и процесс в трудах российских мыслителей XIX-XX вв. Хрестоматия. М.: «Весь Мир», 2003. - С. 607-624.

4. Кальяк А.М. Отдельные вопросы исполнения решений Конституционного Суда РФ в правоприменительной практике // Российская юстиция. 2013. № 9. - С. 36-38.

5. Международные избирательные стандарты. Сборник документов / отв. ред. А.А. Вешняков. М.: Издательство ВЕСЬ МИР, 2004. - 1152 с.

6. Чиркин В. К вопросу о ценности российской Конституции 1993 г. / Актуальные проблемы российского права. 2013. № 12. - С. 1517-1522.

7. Шерстобоев О.Н. Принцип пропорциональности как необходимое условие высылки иностранных граждан за пределы государства их пребывания: пределы правоограничения // Российский юридический журнал. 2011. № 6 (81). - С. 51-59.

8. Эбзеев Б.С. Конституция, власть и свобода в России: опыт синтетического исследования. М.: Проспект, 2014. - 336 с.

9. Cohen-Eliya M., Stopler G. Probability Thresholds as Deontological in Global Constitutionalism // Columbia Journal of Transnational Law. 2011. Vol. 24. № 1. - P. 76-113.

10. Restoring electoral equilibrium in the wake of constituonalized campaign finance // Harvard Law Review. 2011. Vol. 124. № 6. // http://www.harvardlawreview.org/media/pdf/vol124_restoring electoral_equilibrium.pdf (последнее посещение - 25 декабря 2013 г.).

11. Гаврилова Л.В., Игнатенко В.В., Петров А.А., Подшивалов В.Е., Суркова И.С. 0 проверке конституционности в целом Федерального закона от 8 июня 2012 года №65-Ф3 «0 внесении изменений в Кодекс Российской Федерации об административных правонарушениях и Федеральный закон «О собраниях, митингах, демонстрациях, шествиях и п // Актуальные проблемы российского права. - 2013. - 4. - С. 389-410.

\section{References:}

1. Bezrukov A.V., Kazantsev A.O. O neobkhodimosti sozdaniya konstitutsionnykh (ustavnykh) sudov sub"ektov Rossiiskoi Federatsii i sovershenstvovaniya ikh kompetentsii // Sovremennoe pravo. 2012. № 7. - S. 106-111.

2. Borisov I.B., Ivailovskii D.A. Sootnoshenie otdel'nykh pozitsii Evropeiskogo suda po pravam cheloveka s natsional'nym izbiratel'nym zakonodatel'stvom // Konstitutsionnoe i munitsipal'noe pravo. 2009. № 3. - S. 25-29.

3. Gessen V.M. Russkoe Uchreditel'noe sobranie i vybory v nego // Politicheskie instituty, izbiratel'noe pravo i protsess v trudakh rossiiskikh myslitelei KhIKh -KhKh vv. Khrestomatiya. M.: «Ves' Mir», 2003. - S. 607-624.

4. Kal'yakA.M.Otdel'nye voprosy ispolneniya reshenii Konstitutsionnogo Suda RFv pravoprimenitel'noi praktike // Rossiiskaya yustitsiya. 2013. № 9. - S. 36-38.

5. Mezhdunarodnye izbiratel'nye standarty. Sbornik dokumentov / otv. red. A.A. Veshnyakov. M.: Izdatel'stvo VES" MIR, 2004. - 1152 s.

6. Chirkin V. K voprosu o tsennosti rossiiskoi Konstitutsii 1993 g. / Aktual'nye problemy rossiiskogo prava. 2013. № 12. - S. 1517-1522.

7. Sherstoboev O.N. Printsip proportsional'nosti kak neobkhodimoe uslovie vysylki inostrannykh grazhdan za predely gosudarstva ikh prebyvaniya: predely pravoogranicheniya // Rossiiskii yuridicheskii zhurnal. 2011. № 6 (81). - S. 51-59.

8. Ebzeev B.S. Konstitutsiya, vlast' i svoboda v Rossii: opyt sinteticheskogo issledovaniya. M.: Prospekt, 2014. - 336 c.

9. Cohen-Eliya M., Stopler G. Probability Thresholds as Deontological in Global Constitutionalism // Columbia Journal of Transnational Law. 2011. Vol. 24. № 1. - P. 76-113.

10. Restoring electoral equilibrium in the wake of constituonalized campaign finance // Harvard Law Review. 2011. Vol. 124. № 6. // http://www.harvardlawreview.org/media/pdf/vol124_restoring electoral_equilibrium.pdf (poslednee poseshchenie - 25 dekabrya $2013 \mathrm{~g}$.).

11. Gavrilova L.V., Ignatenko V.V., Petrov A.A., Podshivalov V.E., Surkova I.S. O proverke konstitutsionnosti $\mathrm{v}$ tselom Federal'nogo zakona ot 8 iyunya 2012 goda №65-FZ «0 vnesenii izmenenii v Kodeks Rossiiskoi Federatsii ob administrativnykh pravonarusheniyakh i Federal'nyi zakon «O sobraniyakh, mitingakh, demonstratsiyakh, shestviyakh i p // Aktual'nye problemy rossiiskogo prava. - 2013. 4. - C. 389-410. 